\title{
CORRIGENDUM
}

\section{A re-analysis of the iron content of plant-based foods in the United Kingdom - CORRIGENDUM}

\author{
Sylvaine F. A. Bruggraber, Thomas P. E. Chapman, Christopher W. Thane, Ashley Olson,
} Ravin Jugdaohsingh and Jonathan J. Powell

(First published online 18 April 2013)

doi:10.1017/S0007114512000360, Published by Cambridge University Press, 1 March 2012.

We recently reported a contemporary analysis of the Fe content of plant-based foods in the United Kingdom (year 2000 analysis) and compared the results with historical analyses from the $1980 \mathrm{~s}$ and $1930 \mathrm{~s}$. Our Table 2 indicated small but statistically significant differences between the Fe content of (1) fruits between the $1930 \mathrm{~s}$ analyses and the $1980 \mathrm{~s}$ or $2000 \mathrm{~s}$ analysis ( $-0 \cdot 35 \mathrm{and}-0 \cdot 14 \mathrm{mg} /$ $100 \mathrm{~g}$, respectively), (2) vegetables between the $1930 \mathrm{~s}$ and $1980 \mathrm{~s}$ analyses $(-0.17 \mathrm{mg} / 100 \mathrm{~g})$ and (3) cereal products between $1980 \mathrm{~s}$ and $2000 \mathrm{~s}$ analysis $(0.65 \mathrm{mg} / 100 \mathrm{~g}$, most probably due to changes to fortification). While the differences remain accurate, their statistical significance (based on $95 \%$ CI) is not. Due to an error in data transfer, the values reported as $95 \%$ CI (i.e. approximated as mean \pm SE $\times 1.96$ ) were in fact means with their standard errors. The new table below shows corrected $95 \%$ CI and thus that statistical significance remains only for fruits between the $1980 \mathrm{~s}$ and $1930 \mathrm{~s}$. All of the raw data presented in the original paper remain correct. Overall, our messages also remain precisely the same: namely that there is remarkably little difference in the Fe content of vegetables, legumes and pulses and fruits between the $1930 \mathrm{~s}$ and the year 2000 and insufficient published data to allow for comparison of the cereal products, but the issue of modern Fe fortification practices remains a subject of debate. We are most grateful to Donald R. Davis, retired from The University of Texas at Austin, USA, for alerting us to this problem as,

Table 2. (corrected). Differences in the iron content $(\mathrm{mg}$ iron $/ 100 \mathrm{~g}$ food) $\dagger$ of the plantbased food groups between the decadesł

(Number of foods in the group, mean differences, standard deviations and $95 \%$ confidence intervals)

\begin{tabular}{lccc}
\hline & 2000s-1980s & 2000s-1930s & $1980 \mathrm{~s}-1930 \mathrm{~s}$ \\
\hline Fruit & & & \\
$n$ & 29 & 20 & 20 \\
Mean difference & 0.12 & -0.14 & $-0.35^{*}$ \\
SD & 0.66 & 0.53 & 0.76 \\
$95 \% \mathrm{Cl}$ & $-0.12,0.36$ & $-0.37,0.10$ & $-0.68,-0.01$ \\
Vegetables, legumes and pulses & 47 & & $22 \S$ \\
$n$ & 0.08 & -0.09 & -0.17 \\
Mean difference & 0.62 & 0.48 & 0.63 \\
SD & $-0.10,0.26$ & $-0.29,0.11$ & $-0.43,0.09$ \\
$95 \% \mathrm{Cl}$ & & & $\mathrm{nd}$ \\
Cereal products & 41 & $\mathrm{nd}$ & \\
$n$ & 0.65 & & \\
Mean difference & 3.15 & & \\
SD & $-0.31,1.61$ & & \\
$95 \% \mathrm{Cl}$ & & &
\end{tabular}

nd, not determined

* Statistically significant decrease from $1930 \mathrm{~s}$ to $1980 \mathrm{~s}$.

†Values shown are total $\mathrm{Fe}$ content and include the natural Fe content plus any fortificant $\mathrm{Fe}$ where it has been used.

¥The decades compared were: the re-analysis presented in this study (2000 s), the latest literature values (1980s) and the earliest literature values (1930s).

$\S$ Vegetables only due to a lack of data in 1930 s on legumes and pulses. 
using our published raw data, he was able to reconstruct Table 2 and show that the 95\% CI values were, originally, incorrectly reported. As noted above, the table herein is the corrected version ${ }^{(1)}$. The authors apologise for this error.

\section{References}

1. Bruggraber SFA, Chapman TPE, Thane CW, et al. (2012) A re-analysis of the iron content of plant-based foods in the United Kingdom. Br J Nutr 108, 2221-2228, Published by Cambridge University Press, 1 March 2012, doi:10.1017/S0007114512000360. 